\title{
MECHANICAL PROPERTIES OF MODIFIED SUPERSULFATED CEMENT MORTAR
}

\author{
QUANWEN DONG*, LIHUA WAN*, XUMIN LI**, ${ }^{*}$ PENG DU** \\ *Jinan Engineering Quality and Safety Center, Jinan 250014, China \\ **Shandong Provincial Key Laboratory of Preparation \& Measurement of Building Materials, \\ University of Jinan, Jinan 250022, China \\ \#E-mail: mse_dup@ujn.edu.cn
}

Submitted May 8, 2021; accepted July 21, 2021

\begin{abstract}
Keywords: Red mud, Water glass, Modified supersulfated cement, Mechanical property, Microanalysis
Supersulfated cement (SSC) is a green and environmentally friendly material that contains limited or no clinkers, with lowhydration heat release and favorable sulfate corrosion resistance. However, SSC requires modification because its poor mechanical property has restricted its promotion and application to a certain extent. Mix proportion design and mechanical properties of Bayer red mud and water glass-modified SSC were explored in this study, and the results were discussed by microanalysis. Results showed that the increase of red mud content prolongs the setting time of SSC, thereby indicating that early-stage mechanical properties (within 3 days), especially ultraearly-stage mechanical properties (within hours), need further improvement. However, mechanical properties of SSC mortar at different stages improve after three days, and further improve with the simultaneous addition of water glass and red mud. The optimal mix proportion of SSC obtained using Taguchi method is presented as follows: slag (70 wt. \%), gypsum (15 wt. \%), OPC (5 wt. \%), red mud (10 wt. \%), and water glass with a modulus of 1.8 (2.0 wt. \%). Meanwhile, the compressive strength of specimen at this mix proportion reaches $42.12 \mathrm{MPa}$ at $28 \mathrm{~d}$. Mechanical properties improve because system alkalinity is further enhanced, additional gel products are generated, and the hardened body presents a tight binding state due to the simultaneous addition of red mud and water glass.
\end{abstract}

\section{INTRODUCTION}

Main raw materials of supersulfated cement (SSC) are blast-furnace slag, gypsum, and a small quantity of clinker or lime. SSC is a new-type hydraulic cementing material prepared by only using the activator to stimulate the slag activity without relying on traditional cement hydration. The preparation of SSC features low energy consumption and $\mathrm{CO}_{2}$ emission because calcination is unnecessary in the production process. SSC is an energy-saving and environmentally friendly material that contains limited or no clinkers, and its general components include slag $(75-85 \%)$, sulfate [1,2] $(10-20 \%)$, and alkaline components (clinker or alkali activator $[3,4])$. [2, 5, 6] SSC integrates the advantages of lowhydration heat release, microexpansion, and high sulfate corrosion resistance $[7,8]$ but its poor mechanical property [4] restricts its promotion and application to a certain extent.

Studies on alkali-activated materials have shown that the alkali activator content influences the microstructure of hydration products and further affects their mechanical properties, especially early-stage mechanical properties [9-12]. Red mud is an industrial solid waste discharged during aluminum oxide extraction in the aluminum-making industry, and the high alkali content and activity of Bayer red mud considerably restrict its application [13, 14]. The combination of SSC and red mud can effectively utilize not only the red mud to replace slags, which are already transformed from waste into wealth, but also improve mechanical properties of SSC due to the high alkalinity of red mud.

Therefore, Bayer red mud was used in this study to replace slags and serve as both raw material and alkaline activator. A theoretical basis for the modification of SSC was further provided by further adding water glass as the alkaline activator, investigating the mix proportion design and properties of the modified SSC, and conducting microanalysis.

\section{EXPERIMENTAL}

Experimental materials

Ordinary Portland cement (OPC) produced by Shandong Sunnsy Group Co., Ltd. demonstrates a specific surface area of approximately $380 \mathrm{~m}^{2} \mathrm{~kg}^{-1}$ and average grain diameter of $14.97 \mu \mathrm{m}$. Ground granulated blast furnace slag (slag) collected from Jinan Huanghe Luqiao Construction Group Co., Ltd. exhibits an average grain diameter of $10.39 \mu \mathrm{m}$. The average grain diameter of natural gypsum is $9.17 \mu \mathrm{m}$. The Bayer red mud obtained from Shandong Nanshan Aluminum Industry Co., Ltd. shows an average grain diameter of $10.15 \mu \mathrm{m}$. Chemi-cal components of these raw materials are listed in Table 1, and the grain size distribution is shown in Figure 1. 
Dong Q., Wan L., Li X., Du P.

Table 1. Chemical composition of raw materials (wt. \%).

\begin{tabular}{lcrrrrrrrc}
\hline Item & $\mathrm{CaO}$ & $\mathrm{SiO}_{2}$ & $\mathrm{Al}_{2} \mathrm{O}_{3}$ & $\mathrm{Fe}_{2} \mathrm{O}_{3}$ & $\mathrm{SO}_{3}$ & $\mathrm{~K}_{2} \mathrm{O}$ & $\mathrm{Na}_{2} \mathrm{O}$ & $\mathrm{MgO}^{2}$ & $\mathrm{TiO}_{2}$ \\
\hline OPC & 53.25 & 24.41 & 10.59 & 3.24 & 2.95 & 0.59 & 0.38 & 3.35 & 0.54 \\
Slag & 39.20 & 29.42 & 13.86 & - & 3.89 & 0.34 & 0.65 & 7.89 & 0.62 \\
Gypsum & 50.04 & 0.22 & 0.05 & - & 49.35 & 0.02 & 0.03 & 0.11 & - \\
Red mud & 4.75 & 18.41 & 23.17 & 31.14 & 0.61 & - & 13.22 & - & 5.21 \\
\hline
\end{tabular}

Table 2. Performance index of water glass.

\begin{tabular}{lccccc}
\hline & Modulus $n$ & Solid content (wt. \%) & Baume degree & $\mathrm{Na}_{2} \mathrm{O}($ wt. \%) & $\mathrm{SiO}_{2}(\mathrm{wt} . \%)$ \\
\hline Water glass & 3.3 & 34 & 40 & 8.3 & 26.5 \\
\hline
\end{tabular}

The water glass $\left(\mathrm{Na}_{2} \mathrm{O} \cdot \mathrm{nSiO}_{2}\right)$ is an aqueous solution and colorless viscous liquid of sodium silicate produced by GST Holdings Limited, where $\mathrm{n}$ is the modulus. The main property indexes are presented in Table 2 . The modulus of water glass used in the actual experiment of 1.2 - 1.8 was regulated using the chemically pure reagent sodium hydroxide, which was produced by Sinopharm Chemical Reagent Co., Ltd.

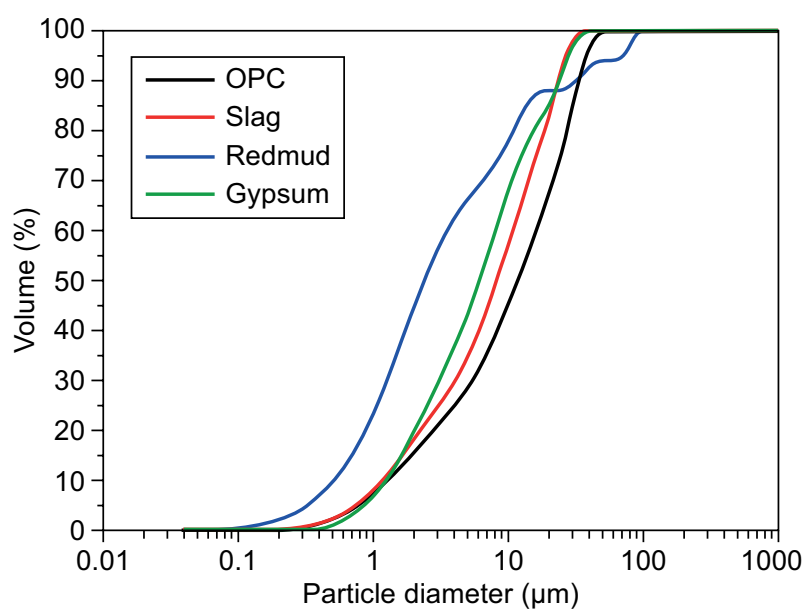

Figure 1. Size distribution of raw materials.

Experimental methods

Setting time and fluidity

Setting time was determined according to Inspection Method of Water Requirement of Normal Consistency of Cement, Setting Time, and Soundness (GB/T 13462011). Mortar fluidity was tested in accordance with Test Method for Fluidity of Cement Mortar (GB/T 24192005).

\section{Mechanical properties}

Mechanical properties (compressive and flexural strength) of SSC were tested according to Method of Testing Cements: Determination of Strength (GB/ T17671-1999), with a cement-to-sand ratio of 1:3. Specimens with a molding size of $40 \times 40 \times 160 \mathrm{~mm}$ were demolded after $24 \mathrm{~h}$ and then put into a curing room at
$20 \pm 2{ }^{\circ} \mathrm{C}$ and $\geq 90 \%$ relative humidity. Strengths were determined at a specified curing age. The average value of three specimens was taken as the final testing result, and the strength value of each specimen was accurate to $0.01 \mathrm{MPa}$.

\section{Taguchi method}

The Taguchi method [15-17] was adopted when the influence of the simultaneous addition of red mud and water glass on fluidity and mechanical properties of SDC were investigated to reduce the number of experimental times. A three-factor (red mud content [C], water glass modulus [M], and water glass content [B]) four-level orthogonal experiment was designed. Levels of orthogonal experimental factors are listed in Table 3. The experiment was carried out according to $\mathrm{L}_{16}$ orthogonal table, and $1.0 \%$ of polycarboxylate superplasticizer was added to each group of specimens.

Table 3. Factor level table of the orthogonal test.

\begin{tabular}{cccc}
\hline Levels & \multicolumn{3}{c}{ Factors } \\
\cline { 2 - 4 } & $\begin{array}{c}\text { Red mud } \\
\text { content } \\
(\mathrm{C}, \text { wt. \%) }\end{array}$ & $\begin{array}{c}\text { Modulus of } \\
\text { water glass } \\
(\mathrm{M})\end{array}$ & $\begin{array}{c}\text { Dosage of water } \\
\text { water glass } \\
\text { (B, wt. \%) }\end{array}$ \\
\hline 1 & 5 & 1.2 & 0.5 \\
2 & 10 & 1.4 & 1.0 \\
3 & 15 & 1.6 & 1.5 \\
4 & 20 & 1.8 & 2.0 \\
\hline
\end{tabular}

Signal-to-noise ratio $(\mathrm{S} / \mathrm{N})$ is a core tool of the Taguchi method. The optimal parameter combination can be obtained through computational analysis of $\mathrm{S} / \mathrm{N}$. The calculation of $\mathrm{S} / \mathrm{N}$ is divided into three types, namely, large-the-best, small-the-best, and nominal-the-best types [17], as follows:

$$
\begin{gathered}
S / N=-10 \log _{10}\left(\frac{1}{n} \sum_{i=1}^{n} \frac{1}{Y_{i}^{2}}\right), \\
S / N=-10 \log _{10}\left(\frac{1}{n} \sum_{i=1}^{n} Y_{i}^{2}\right), \\
S / N=-10 \log _{10}\left(\frac{1}{n} \sum_{i=1}^{n}\left(Y_{i}-Y_{0}\right)^{2}\right),
\end{gathered}
$$


where $Y_{i}$ is the experimental value of the experiment $i$ and $n$ represents the number of experimental repetitions. Mechanical properties of mortar were considered the main indexes in this study. Mortar with high mechanical properties is considered ideal, the $\mathrm{S} / \mathrm{N}$ formula is chosen to adopt large-the-best. In addition, the mean value analysis of corresponding indexes was implemented, that is, the mean value of four results was obtained by taking corresponding levels of correlated factors.

\section{Others}

An X-ray diffractometer (D8 Advance, Brooker Corporation, German) was used for the phase analysis of hydration products. Meanwhile, a field emission scanning electron microscope (MERLIN Compact, ZEISS, German) was used to analyze the microstructure of the hardened body. The porosity of sample was calculated by using $2 \mathrm{D}$ of electron microscope images magnified 200 times.

\section{RESULTS}

\section{Influence of red mud on SSC properties}

Table 4 shows that the addition of red mud prolongs the setting time of SSC. Moreover, if the setting time clearly extended with the increase of the red mud content, then the activity of red mud reduced and the decreased

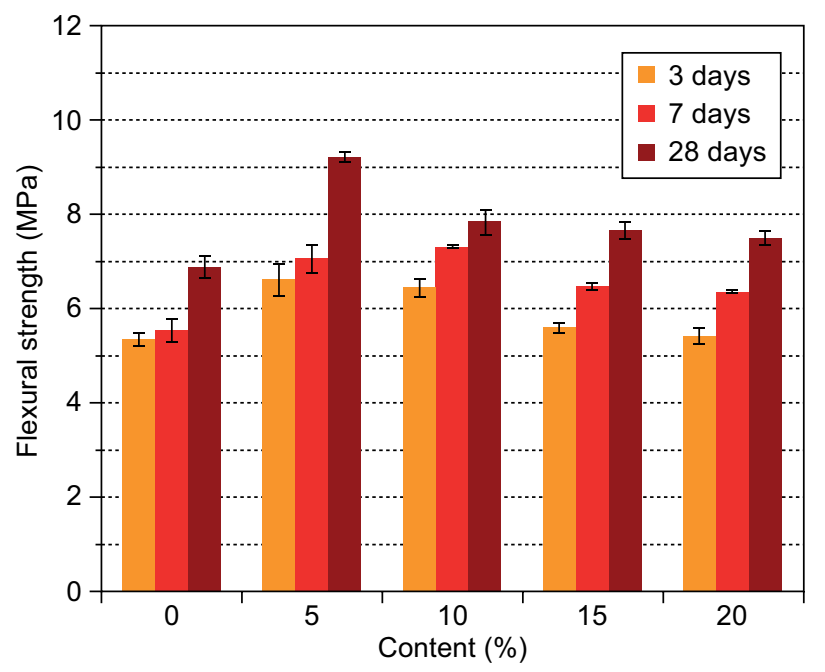

a) slag content delayed the setting and hardening of SSC. Although the addition of red mud improved the system alkalinity and stimulated the slag activity to a certain extent, the alkalinity was insufficient to compensate for the negative impacts caused by the low activity of red mud. Therefore, the amount of alkaline solution should be increased to activate the early-stage strength, especially ultraearly-stage strength, of SSC.

Figure 2 shows that both flexural and compressive strength values of specimens first increased and then decreased at each stage after 3 days with the increase of the red mud content and are higher than those of the specimen in the blank control group. The flexural strength of specimens at a red mud content of $5 \mathrm{wt}$ \% was the highest after 28 days at $9.21 \mathrm{MPa}$, which was $33.87 \%$ higher than the specimen in the blank control group. This finding indicated that mechanical properties of SSC can improve with the addition of red mud.

Influence of the simultaneous addition of water glass and red mud on SSC properties

\section{Fluidity}

The fluidity test results of 16-group SSC mortar specimens with different mix proportions are listed in Table 5. The results of $\mathrm{S} / \mathrm{N}$ and mean value analyses are illustrated in Figure 3. The $\mathrm{S} / \mathrm{N}$ results demonstrated that

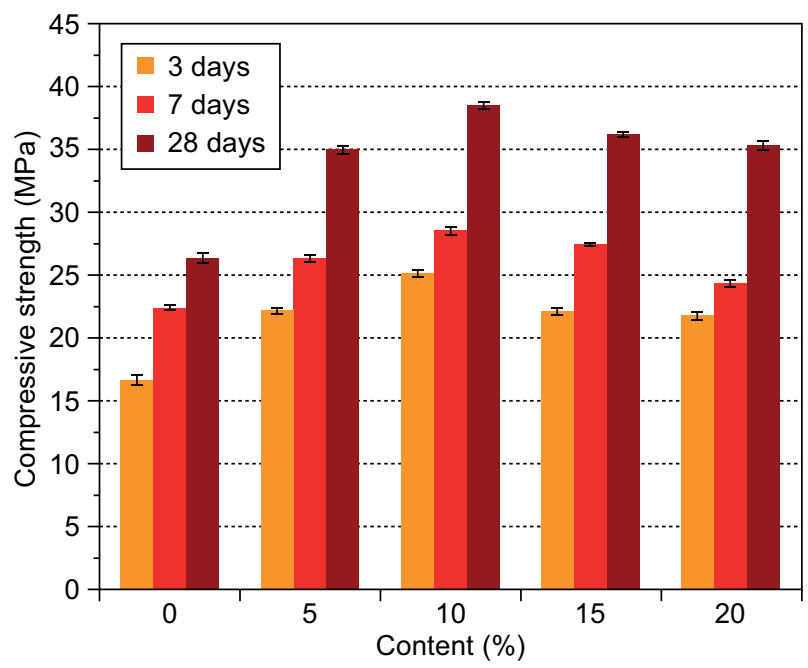

b)

Figure 2. Effect of red mud content on mechanical properties of SSC.

Table 4. Effect of red mud content on setting time of SSC.

\begin{tabular}{|c|c|c|c|c|c|c|c|}
\hline \multirow{2}{*}{ No. } & \multirow{2}{*}{$\begin{array}{c}\text { Slag } \\
\text { (wt. \%) }\end{array}$} & \multirow{2}{*}{$\begin{array}{l}\text { Red mud } \\
\text { (wt. \%) }\end{array}$} & \multirow{2}{*}{$\begin{array}{l}\text { Gypsum } \\
\text { (wt. \%) }\end{array}$} & \multirow{2}{*}{$\begin{array}{c}\text { OPC } \\
\text { (wt. \%) }\end{array}$} & \multirow{2}{*}{$\begin{array}{c}\text { Polycarboxylate } \\
\text { superplasticizer (wt. \%) }\end{array}$} & \multicolumn{2}{|c|}{ Setting time $(\min )$} \\
\hline & & & & & & Initial & Final \\
\hline A1 & 80 & 0 & 15 & 5 & 1 & 6 & 14 \\
\hline A2 & 75 & 5 & 15 & 5 & 1 & 10 & 21 \\
\hline A3 & 70 & 10 & 15 & 5 & 1 & 12 & 32 \\
\hline A4 & 65 & 15 & 15 & 5 & 1 & 18 & 47 \\
\hline A5 & 60 & 20 & 15 & 5 & 1 & 23 & 54 \\
\hline
\end{tabular}


the response sequence of factors of $\mathrm{B}>\mathrm{C}>\mathrm{M}$ influence the mortar fluidity. Hence, the water glass content exerted the greatest influence on the mortar fluidity and the fluidity reduced with the increase of the water glass content, followed by the influence of red mud content on the mortar fluidity. The fluidity increased and then decreased with the increase of the red mud content and reached the maximum value at a red mud content of 15 wt. \%. The mortar fluidity was influenced by the modulus of water glass to the minimum extent. As shown in Figure 3b, ranges of C, M, and B were 15.3, 13.0, and 33.5, respectively, and the response sequence was identical with that of the $\mathrm{S} / \mathrm{N}$ analysis at $\mathrm{B}>\mathrm{C}>\mathrm{M}$. $\mathrm{S} / \mathrm{N}$ and (B) average value analyses.

\section{Mechanical properties}

The test results of mechanical properties are listed in Table 5. The results showed that mechanical properties of No. 6 specimen are optimal at 3, 7, and 28 days,

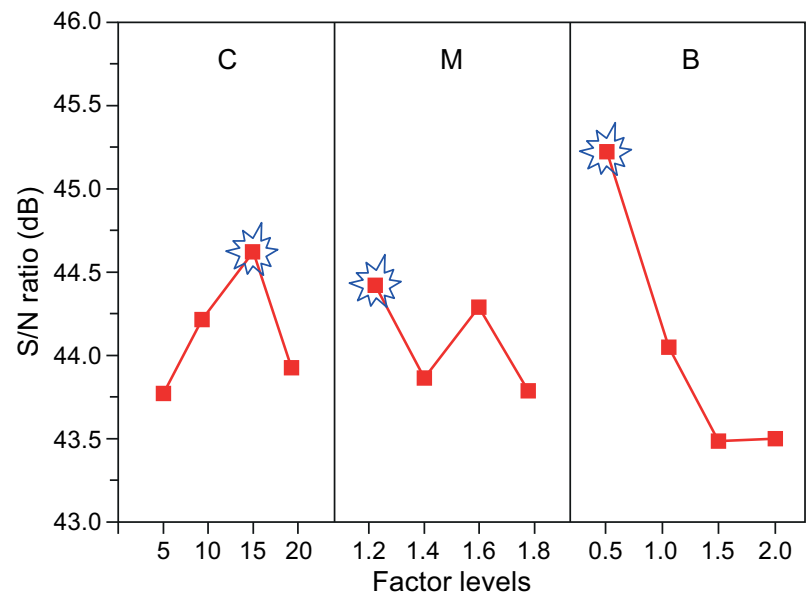

a) with compressive strength values of $21.44,32.07$, and 41.41 $\mathrm{MPa}$ and flexural strength values of 5.20, 7.24, and $10.46 \mathrm{MPa}$, respectively. The $\mathrm{S} / \mathrm{N}$ analysis results of mechanical properties are shown in Figure 4. The response sequence of factors that influence mechanical properties was $\mathrm{M}>\mathrm{B}>\mathrm{C}$; hence, the modulus of water glass exerted the greatest influence on mechanical properties of mortar. Specifically, flexural and compressive strength values of specimens improved with the increase of modulus of water glass, followed by the influence of water glass content on mechanical properties of mortar. Flexural and compressive strength values presented an overall rising trend as the water glass content increased. The red mud content exerted the minimum influence on mechanical properties of mortar. Flexural and compressive strength values first increased and then decreased with the increase of the red mud content. The results of the mean value analysis of mechanical properties are illustrated in Figure 5. Mean values of flexural and compressive

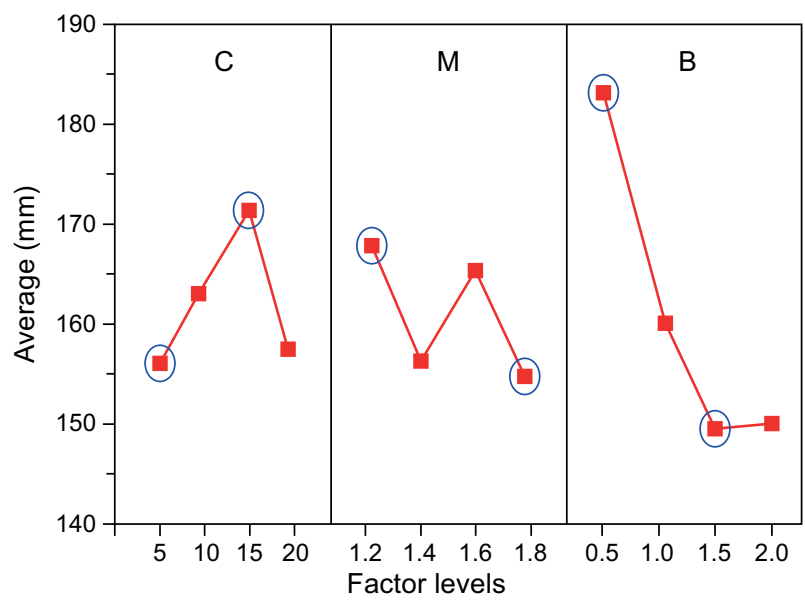

b)

Figure 3. Analysis of fluidity results of SSC mortar: a) S/N and b) average value analyses.

Table 5. Test results of fluidity mechanical properties.

\begin{tabular}{|c|c|c|c|c|c|c|c|c|c|c|}
\hline \multirow{2}{*}{ No. } & \multirow{2}{*}{$\mathrm{C}$} & \multirow{2}{*}{ M } & \multirow{2}{*}{$\mathrm{B}$} & \multirow{2}{*}{$\begin{array}{c}\text { Fluidity } \\
\text { (mm) }\end{array}$} & \multicolumn{3}{|c|}{ Flexural strength $(\mathrm{MPa})$} & \multicolumn{3}{|c|}{ Compressive strength (MPa) } \\
\hline & & & & & $3 \mathrm{~d}$ & $7 \mathrm{~d}$ & $28 \mathrm{~d}$ & $3 \mathrm{~d}$ & $7 \mathrm{~d}$ & $28 \mathrm{~d}$ \\
\hline 1 & 5 & 1.4 & 1.0 & 142 & 5.37 & 6.39 & 7.24 & 16.51 & 21.14 & 30.43 \\
\hline 2 & 5 & 1.2 & 0.5 & 197 & 4.39 & 6.01 & 6.43 & 16.31 & 21.61 & 28.35 \\
\hline 3 & 10 & 1.8 & 1.5 & 144 & 5.60 & 7.38 & 9.51 & 18.36 & 26.16 & 37.68 \\
\hline 4 & 5 & 1.6 & 1.5 & 137 & 4.67 & 6.79 & 10.29 & 16.60 & 22.98 & 30.48 \\
\hline 5 & 20 & 1.6 & 1.0 & 162 & 6.35 & 7.34 & 8.57 & 18.57 & 24.12 & 31.25 \\
\hline 6 & 5 & 1.8 & 2.0 & 148 & 5.20 & 7.24 & 10.46 & 21.44 & 32.07 & 41.41 \\
\hline 7 & 20 & 1.2 & 2.0 & 139 & 5.28 & 5.76 & 6.84 & 15.61 & 19.81 & 27.33 \\
\hline 8 & 15 & 1.8 & 1.0 & 158 & 5.35 & 7.09 & 8.43 & 17.47 & 25.21 & 32.57 \\
\hline 9 & 15 & 1.6 & 0.5 & 199 & 5.31 & 5.43 & 8.19 & 16.53 & 23.19 & 27.53 \\
\hline 10 & 20 & 1.8 & 0.5 & 169 & 4.39 & 6.17 & 7.69 & 16.02 & 24.08 & 27.40 \\
\hline 11 & 15 & 1.4 & 2.0 & 149 & 5.00 & 6.69 & 8.16 & 16.62 & 24.97 & 28.34 \\
\hline 12 & 10 & 1.4 & 0.5 & 167 & 5.06 & 5.49 & 8.02 & 16.43 & 23.17 & 27.83 \\
\hline 13 & 10 & 1.6 & 2.0 & 163 & 5.82 & 8.28 & 8.54 & 18.21 & 31.14 & 39.51 \\
\hline 14 & 10 & 1.2 & 1.0 & 178 & 5.63 & 6.41 & 8.63 & 16.37 & 27.47 & 29.56 \\
\hline 15 & 20 & 1.4 & 1.5 & 160 & 5.31 & 5.86 & 8.91 & 16.20 & 21.69 & 30.38 \\
\hline 16 & 15 & 1.2 & 1.5 & 157 & 5.33 & 5.44 & 7.18 & 15.11 & 19.19 & 24.39 \\
\hline
\end{tabular}


strength after $28 \mathrm{~d}$ were calculated, and flexural strength values of $\mathrm{C}, \mathrm{M}$, and $\mathrm{B}$ were $0.69,1.75$, and 0.92 and compressive strength values were $4.56,7.36$, and 6.37 , respectively. The response sequence of $\mathrm{M}>\mathrm{B}>\mathrm{C}$ was clearly consistent with that of the $\mathrm{S} / \mathrm{N}$ analysis results.

The experimental results were comprehensively analyzed, and the optimal mix proportion (BMP) of modified SSC was slag (70 wt. \%), gypsum (15 wt. \%), OPC (5 wt. \%), red mud (10 wt. \%), and water glass with a modulus of 1.8 (2.0 wt. \%). The experiment with the Taguchi method showed that the compressive strength is $40.75 \mathrm{MPa}$ after 28 days at the BMP. The compressive strength of the specimen group was measured to assess the accuracy of prediction results. The experimental results are listed in Table 6 . The compressive strength after 28 days was experimentally measured at $42.12 \mathrm{MPa}$ and the error with the predicted value was smaller than $5 \%$, thereby indicating that the prediction results are reliable.

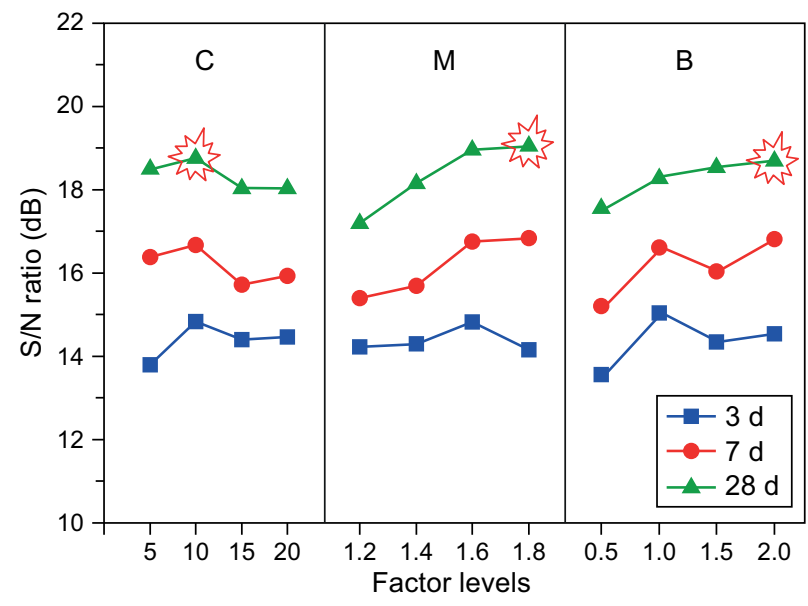

a)
Table 6. Comparison of actual and predicted compressive strength values of the optimal mix proportion.

\begin{tabular}{llcc}
\hline & \multicolumn{3}{c}{ Compressive strength $(\mathrm{MPa})$} \\
\cline { 2 - 4 } & 3 days & 7 days & 28 days \\
\hline Actual value & 23.32 & 32.57 & 42.12 \\
Predicted value & 22.26 & 32.36 & 40.75 \\
\hline
\end{tabular}

\section{DISCUSSION}

Microanalysis was performed by selecting the blank control specimen (Blank), the specimen with red mud content of $10 \mathrm{wt}$ \% (A3) and the specimen with the optimal mix proportion (BMP). Figure 6 presents that the main mineral compositions in mortar specimens of all groups are ettringite (AFt) and gypsum and the characteristic peak of AFt increases while that of gypsum decreases with the increase of age. This finding indicated

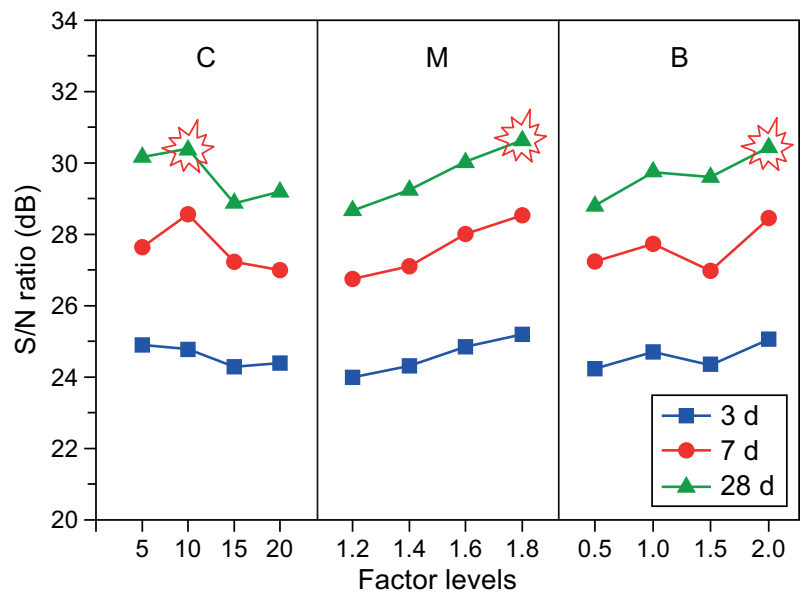

b)

Figure 4. S/N analysis results of mechanical properties of SSC mortar: a) flexural strength and b) compressive strength.

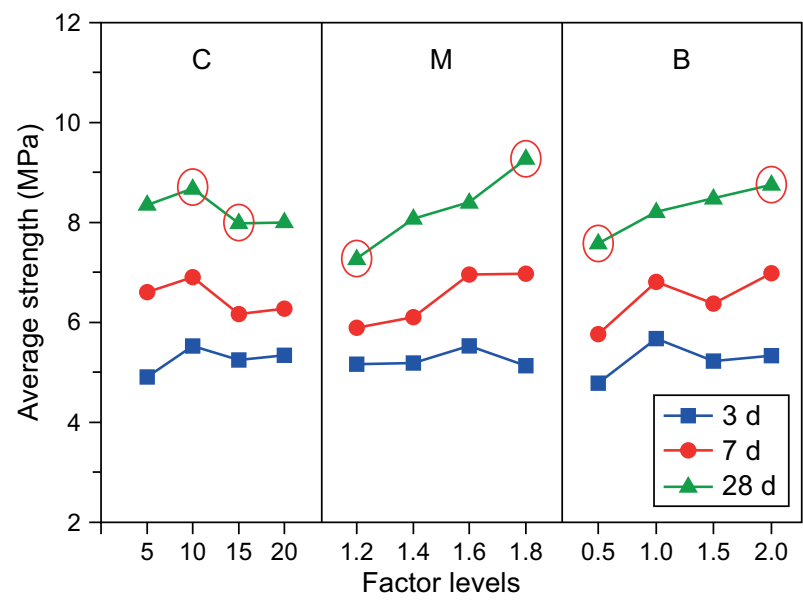

a)

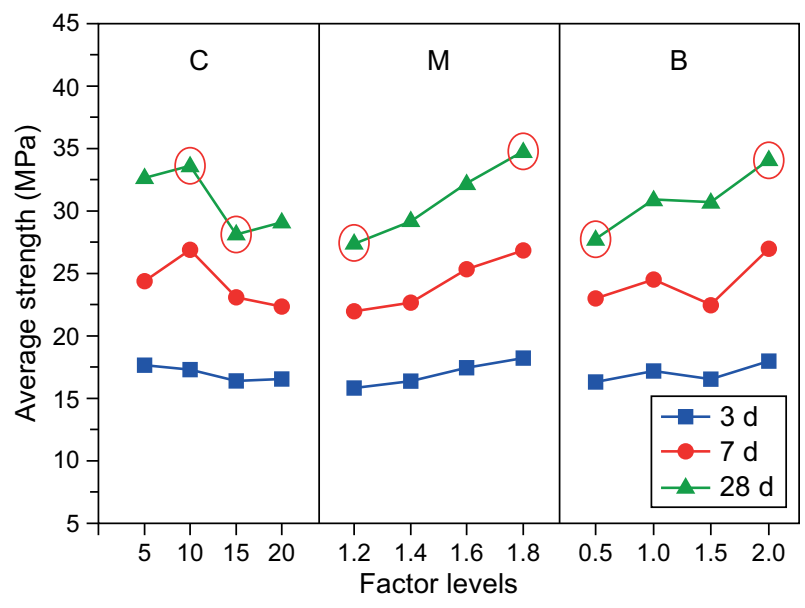

b)

Figure 5. Average value analysis results of mechanical properties of SSC mortar: a) flexural strength and b) compressive strength. 
that gypsum continuously participates in the reaction and is consumed throughout the process of hydration reaction while partially unreacted gypsum still exists at 28 days. The comparative analysis indicated that the characteristic peak of AFt in the XRD diffractogram of the BMP specimen is clearly weaker than that of

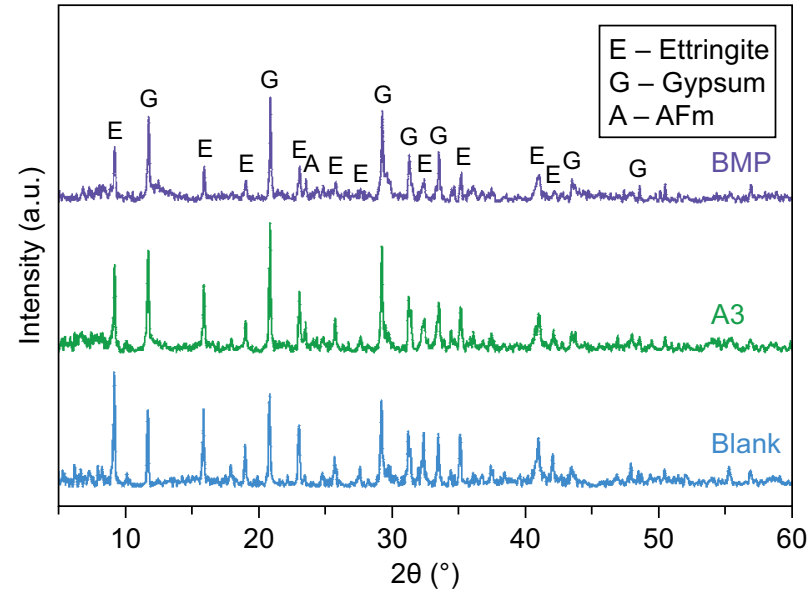

a)

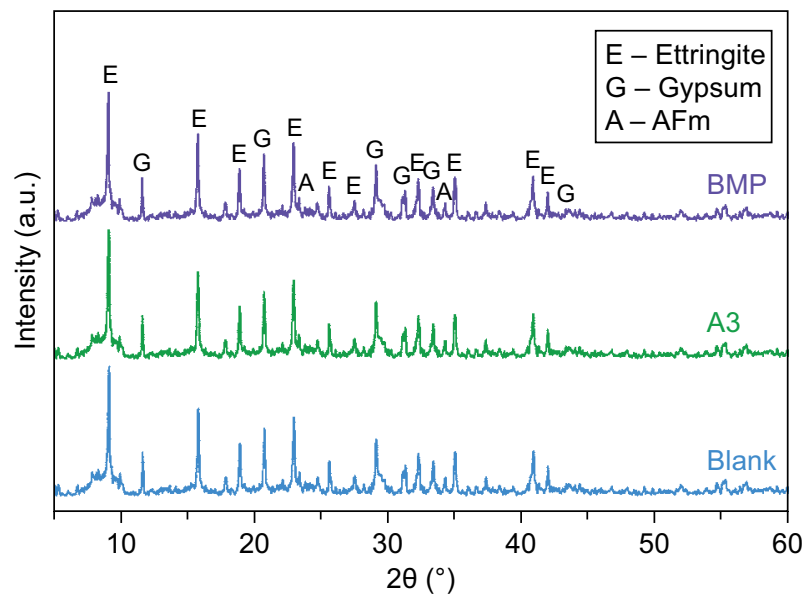

b)

Figure 6. XRD patterns of hydration products in each group: a) 3 days and b) 28 days.
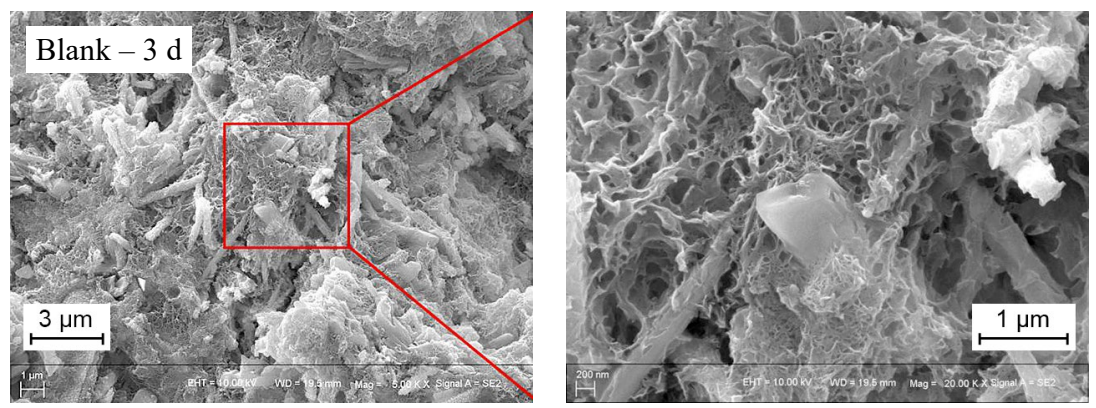

a)
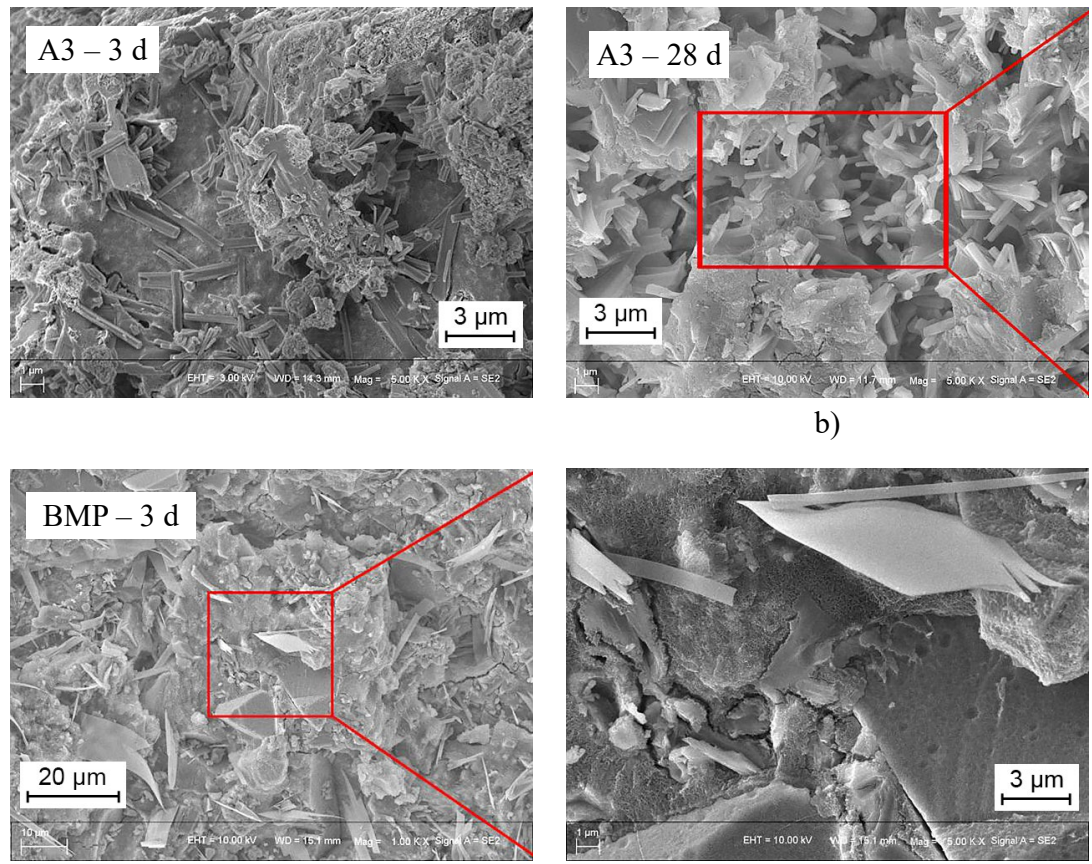

b)

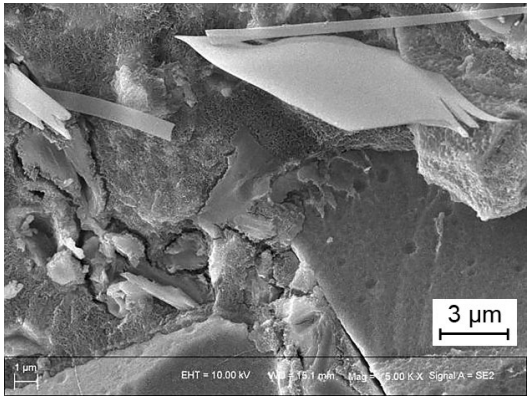

c)
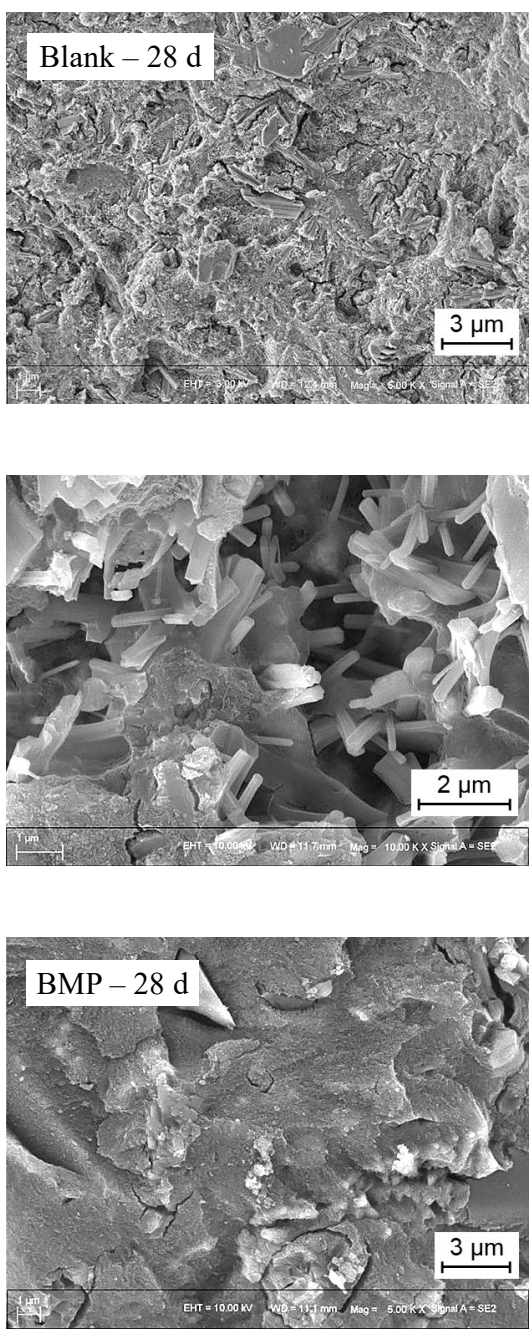

Figure 7. Micromorphology of samples in each group at 3 and 28 days. 
specimens in the two other groups at each age, especially at 3 days of hydration. By contrast, the peak value of monosulfate-hydrated calcium sulfoaluminate (AFm) was high because the $\mathrm{pH}$ value of the porous solution in the system is an important factor that influences the formation of AFt. The large quantity of generated $\mathrm{C}-\mathrm{S}-\mathrm{H}$ and $\mathrm{C}-\mathrm{A}-\mathrm{S}-\mathrm{H}$ gels consumes $\mathrm{SO}_{4}{ }^{2-}$ in a considerable amount when the $\mathrm{pH}$ value of the porous solution is excessively high. As a result, the sulfur needed to generate AFt is insufficient $[18,19]$ and AFm is then generated.

Figure 7a shows the large size of needle-like AFt in the hydration product of SSC that cross and adhere to the $\mathrm{C}-\mathrm{S}-\mathrm{H}$ gel. Hence, strength was generated in the hardened body but large crystals impeded the continuity of $\mathrm{C}-\mathrm{S}-\mathrm{H}$ coagulation and limited the strength development. As shown in Figure $7 b$, the system alkalinity of the A3 specimen system enhanced and thus generated highalkalinity $\mathrm{C}-\mathrm{S}-\mathrm{H}$ gel that presented "scale" morphology due to the addition of high-alkalinity Bayer red mud [20]. The moderate increase of alkalinity was consistent with generation conditions of $\mathrm{AFt}$ and active $\mathrm{Al}_{2} \mathrm{O}_{3}$ in the raw material interacted with gypsum and $\mathrm{Ca}(\mathrm{OH})_{2}$ to generate a large quantity of small needle-like AFt structures [18, 19]. Such AFt structures with regular shape grow in the $\mathrm{C}-\mathrm{S}-\mathrm{H}$ gel in an interspersed manner. They continuously generated and jointly filled pores of the slurry to form a continuous reticular structure that improved the pore structural distribution of mortar and its mechanical properties.

Figure 7c shows that a large quantity of gel products are generated because the water glass can improve the degree of gel polymerization in the system and also increase the gel quantity [21]. Moreover, C-S-H presented a "foil" morphology in the initial hydration phase because the increase in the $\mathrm{pH}$ value of the system caused by the addition of water glass is correlated with the $\mathrm{C}-\mathrm{S}-\mathrm{H}$ morphology and $\mathrm{C}-\mathrm{S}-\mathrm{H}$ is generally "foil"shaped under $\mathrm{pH}>11[22,23]$. A considerable amount of $\mathrm{C}-\mathrm{S}-\mathrm{H}$ gel was generated and cemented into a whole throughout the hydration reaction process. This cementing process increased the density of the matrix (BMP has the lowest porosity shown as Fig. 8) and further improved mechanical properties. Figure $7 \mathrm{c}$ presents that the small quantity of AFt is accompanied by the generation of AFm. This finding is consistent with the XRD analysis results.

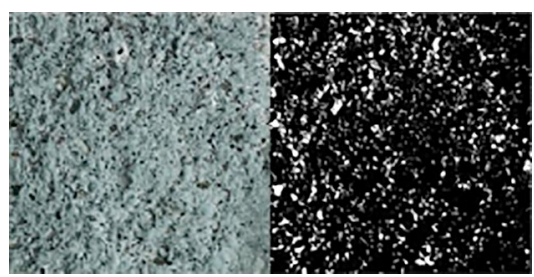

a) Blank $11.38 \%$

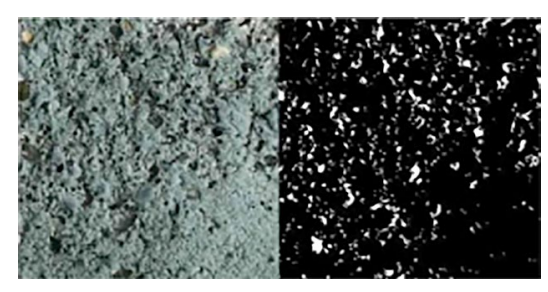

b) A3 $7.26 \%$

\section{CONCLUSIONS}

- The setting time of SSC prolonged with the increase of the red mud content when only the red mud was added to SSC. Both flexural and compressive strength values of specimens first increased and then decreased after 3 days at different ages, with both values higher than those of the specimen in the blank control group. This finding indicated that the addition of red mud can improve mechanical properties of SSC in the later phase. The compressive strength of specimens reached the maximum value (38.50 MPa) of $46.00 \%$ at 28 days under a red mud content of $10 \mathrm{wt}$ \%. This finding was higher than that of the blank control group.

- The $\mathrm{L}_{16}$ orthogonal table was used to investigate the influence of the simultaneous addition of water glass and red mud on properties of the SSC mortar. The experimental results were calculated and analyzed using the Taguchi method. The results showed that the response sequence of factors that influence mechanical properties of mortar is modulus of water glass $>$ water glass content $>$ red mud content. The optimal mix proportion of SSC was slag (70 wt. \%), gypsum (15 wt. \%), OPC (5 wt. \%), red mud (10 wt. \%), and water glass with a modulus of 1.8 (2.0 wt. \%). The compressive strength of specimens at this mix proportion reached $42.12 \mathrm{MPa}$ after 28 days.

- Main hydration products of SSC were AFt and C-S-H gels along with a small quantity of unreacted gypsum. The system alkalinity elevated, the $\mathrm{C}-\mathrm{S}-\mathrm{H}$ gel showed the "scale" morphology, and needle-like AFt with small size and regular shape was generated with the addition of red mud. The continuous increase of system alkalinity and generation of additional gel products due to the simultaneous addition of red mud and water glass tightly bound the hardened body and thus improved mechanical properties of SSC mortar. However, the formation of $\mathrm{AFt}$ was impeded by the consumption of additional $\mathrm{SO}_{4}{ }^{2-}$ of generated gels that led to the generation of AFm.

\section{Acknowledgments}

Supports from the Key Special Project of "Science and Technology for Economy 2020" (Grant No. 2020YFB0312100ZL) and the 111 Project of International Corporation on Advanced Cement-based Materials (Grant No. D17001) are greatly acknowledged.

Figure 8. Porosity of samples in each group at 28 days. 


\section{REFERENCES}

1. Rubert S., da Luz C. A., Varela M. V. F., Pereira Filho J. I., Hooton R. D. (2018): Hydration mechanisms of supersulfated cement. Journal of Thermal Analysis and Calorimetry, 134(2), 971-980. doi: 10.1007/s10973-018-7243-6

2. Da Luz C. A., Hooton R. D. (2015): Influence of curing temperature on the process of hydration of supersulfated cements at early age. Cement and Concrete Research, 77, 69-75. doi: 10.1016/j.cemconres.2015.07.002

3. Masoudi R., Hooton R. D. (2020): Influence of alkali lactates on hydration of supersulfated cement. Construction and Building Materials, 239, 117844. doi: 10.1016/j.conbuildmat.2019.117844

4. Zhou, Y., Peng, Z., Chen, L., Huang, J., \& Ma, T. (2021). The influence of two types of alkali activators on the microstructure and performance of supersulfated cement concrete: mitigating the strength and carbonation resistance. Cement and Concrete Composites, 118, 103947. doi: 10.1016/j. cemconcomp.2021.103947

5. Gruskovnjak A., Lothenbach B., Winnefeld F., Figi R., Ko S. C., Adler M., Mäder U. (2008): Hydration mechanisms of super sulphated slag cement. Cement and Concrete Research, 38(7), 983-992. doi: 10.1016/j.cemconres.2008. 03.004

6. Pinto S. R., da Luz C. A., Munhoz G. S., MedeirosJunior R. A. (2020): Durability of phosphogypsum-based supersulfated cement mortar against external attack by sodium and magnesium sulfate. Cement and Concrete Research, 136, 106172. doi: 10.1016/j.cemconres.2020. 106172

7. Wu Q., Xue Q., Yu Z. (2021): Research status of super sulfate cement. Journal of Cleaner Production, 294, 126228. doi: 10.1016/j.jclepro.2021.126228

8. Juenger M. C. G., Winnefeld F., Provis J. L., Ideker J. H. (2011): Advances in alternative cementitious binders. Cement and Concrete Research, 41(12), 1232-1243. doi: 10.1016/j.cemconres.2010.11.012

9. Zhang Z., Wang H., Provis J. L., Bullen F., Reid A., Zhu Y. (2012): Quantitative kinetic and structural analysis of geopolymers. Part 1. The activation of metakaolin with sodium hydroxide. Thermochimica acta, 539, 23-33. doi: 10.1016/j.tca.2012.03.021

10. Gao X., Yu Q. L., Brouwers H. J. H. (2015): Properties of alkali activated slag-fly ash blends with limestone addition. Cement and Concrete Composites, 59, 119-128. doi: 10.1016/j.cemconcomp.2015.01.007

11. Gijbels K., Iacobescu R. I., Pontikes Y., Schreurs S., Schroeyers W. (2019): Alkali-activated binders based on ground granulated blast furnace slag and phosphogypsum. Construction and Building Materials, 215, 371-380. doi: 10.1016/j.conbuildmat.2019.04.194
12. Li X., Zhang Q., Mao S. (2021): Investigation of the bond strength and microstructure of the interfacial transition zone between cement paste and aggregate modified by Bayer red mud. Journal of Hazardous Materials, 403, 123482. doi: 10.1016/j.jhazmat.2020.123482

13. Du P., Zhou T., Zhao P., Zhou Z., Liu Y., Cheng X. (2018): Efflorescence Inhibition of Alkali-Activated Steel Slag-Slag Material By Nano $\mathrm{SiO}_{2}$. Ceramics-Silikáty, 62(3), 285-292.

14. Liu S., Li Z., Li Y., Cao W. (2018): Strength properties of Bayer red mud stabilized by lime-fly ash using orthogonal experiments. Construction and Building Materials, 166, 554-563. doi: 10.1016/j.conbuildmat.2018.01.186

15. Panagiotopoulou C., Tsivilis S., Kakali G. (2015): Application of the Taguchi approach for the composition optimization of alkali activated fly ash binders. Construction and Building Materials, 91, 17-22. doi: 10.1016/j.conbuildmat. 2015.05.005

16. Hoseinpour-Lonbar M., Alavi M. Z., Palassi M. (2020): Selection of asphalt mix with optimal fracture properties at intermediate temperature using Taguchi method for design of experiment. Construction and Building Materials, 262, 120601. doi: 10.1016/j.conbuildmat.2020.120601

17. Sharifi E., Sadjadi S. J., Aliha M. R. M., Moniri A. (2020): Optimization of high-strength self-consolidating concrete mix design using an improved Taguchi optimization method. Construction and Building Materials, 236, 117547. doi: 10.1016/j.conbuildmat.2019.117547

18. Sun G., Zhang J., Yan N. (2020): Microstructural evolution and characterization of ground granulated blast furnace slag in variant $\mathrm{pH}$. Construction and Building Materials, 251, 118978. doi: 10.1016/j.conbuildmat.2020.118978

19. Gijbels K., Pontikes Y., Samyn P., Schreurs S., Schroeyers W. (2020): Effect of $\mathrm{NaOH}$ content on hydration, mineralogy, porosity and strength in alkali/sulfate-activated binders from ground granulated blast furnace slag and phosphogypsum. Cement and Concrete Research, 132, 106054. doi: 10.1016/j.cemconres.2020.106054

20. Zhao X.G. (2010). Synthesis, Composition and Morphology of Hydrated Calcium Silicate. Wuhan University of Technology.

21. Wang D.P. (2018). Research on Shrinkage Characteristics of Alkali Slag / Fly ash Composite Cementitious Materials. Anhui University of Science and Technology.

22. Plank J., Schönlein M., Kanchanason V. (2018): Study on the early crystallization of calcium silicate hydrate (CSH) in the presence of polycarboxylate superplasticizers. Journal of Organometallic Chemistry, 869, 227-232. doi: 10.1016/j. jorganchem.2018.02.005

23. Schönlein M., Plank J. (2018): A TEM study on the very early crystallization of $\mathrm{CSH}$ in the presence of polycarboxylate superplasticizers: Transformation from initial CSH globules to nanofoils. Cement and Concrete Research, 106, 33-39. doi: 10.1016/j.cemconres.2018.01.017 